\title{
Bruno de Hezeta y Fray Miguel de la Campa: los parajes del miedo en la exploración en la costa del Pacífico en el Noroeste norteamericano (1775).
}

José M. García-Sánchez

Eastern Washington University

jgarcia@ewu.edu

\begin{abstract}
This study focuses on the navigation diaries about the Pacific Northwest coast of North America of Bruno de Hezeta and Fray Miguel de la Campa (1775), employing the postcolonial discursive analysis that humanistic geography has provided. Both logs are scrutinized with respect to the landscapes and contacts that the colonizing subject perceives for the first time. The contrast between both accounts, one narrated by a navigator and the other by a chaplain, reveals the narrative constructions and the identity of the subjects themselves with respect to the peripheral landscapes they encountered. These representations are defined by the construction of fear that Yi-Fu Tuan (2014) uses to frame the
\end{abstract}


boundaries of domination, home, and body that most cultures demarcate in their spatial imagery.

Keywords: Pacific Northwest; exploration; eighteenth century

\begin{abstract}
Resumen
Este estudio se concentra en los diarios de navegación en la costa del Pacífico Noroeste de Norteamérica de Bruno de Hezeta y Fray Miguel de la Campa (1775), mediante el análisis discursivo postcolonial que la geografía humanística ha proporcionado. Ambos diarios son puestos a escrutinio con respecto a los parajes y los contactos que el sujeto colonizador avista por primera vez. Al contrastar ambos relatos, uno narrado por un navegante y otro por un capellán, se ponen de manifiesto las construcciones narrativas y la identidad de los propios sujetos con respecto a tales parajes periféricos. Estas representaciones vienen definidas por la construcción del miedo que Yi-Fu Tuan (2014) enmarca en las fronteras del dominio, el hogar, y el cuerpo que la mayoría de las culturas delimitan en su imaginario espacial.
\end{abstract}

Palabras clave: Costa Noroeste del Pacifico; exploración; siglo XVIII

esde el encuentro colombino se siguieron prodigando los logros geográficos que supusieron una nueva concepción visionaria del globo terráqueo. Como señala Yi-Fu Tuan, la cosmografía renacentista tuvo una tendencia a sobrestimar las dimensiones de la tierra frente al mar, paradoja que hizo posible que Cristóbal Colón llegara al continente americano al errar el cálculo de esas superficies. Respecto a algunos de los resultados puestos en perspectiva por las exploraciones del Noroeste del Pacífico y el desarrollo que la geografía física alcanzó desde el siglo XV, cabe destacar el establecimiento de la verdadera dimensión de los océanos, la consecución plena del territorio que conformaba el continente tras la exploración de sus costas, así como acabar supuestamente con el mito del paso del Noroeste del Pacífico. El mito del paso norte del Océano Pacífico al Atlántico se remonta a las evocaciones y 
especulaciones que protagonizaron a lo largo de los siglos marinos y viajeros como Juan de Fuca, Lorenzo Ferrer Maldonado, Juan Rodríguez Cabrillo, o Alvar Núñez Cabeza de Vaca. Todos ellos conjeturaron respecto al estrecho legendario de Anían y la Quivira, y seguirían otras menciones que situarían el supuesto paso entre el Pacífico y el Atlántico en los sesenta grados. No es menos cierto que la búsqueda de ese mítico paso del Noroeste ha recobrado vigencia a la luz del cambio climático, hecho que ha dado lugar a que se fomente su viabilidad y vigencia. La banquisa de hielo ha sido errática con una tendencia generalizada a su disminución, haciendo que algunos veranos sea navegable (National Snow and Sea Data Center). Desafortunadamente, ello implica que ese periplo del viaje se vea sometido a futuras explotaciones dado los inmensos recursos que posee.

La escuela de Guardiamarinas de Cádiz proveyó a finales del siglo XVIII a las expediciones de esta zona el principal contingente de oficiales ante las noticias llegadas a Madrid que relataban la expansión peletera rusa en las aguas septentrionales del Océano Pacífico. Estos oficiales, por orden expresas de Carlos III al Virrey Frey Antonio María Bucareli serían "mozos expertos y hábiles que pudiesen, con las embarcaciones que vuestra excelencia tenga en San Blas, trillar aquellos mares hasta Monterrey y más arriba si pudiese" (Bernabéu Albert 43). Entre los oficiales más notables enviados a México, figuraron los tenientes de fragata Bruno de Hezeta, Ignacio Arteaga, Francisco Quirós, Miguel Manrique y los alféreces Juan Francisco de la Bodega y Quadra, Juan de Ayala y Diego Choquet. A su llegada a Veracruz, descubrieron que el piloto Juan Joseph Pérez ya había hecho un viaje de reconocimiento en 1774, en una primera fase hasta Monterrey (Alta California) y posteriormente hasta el fondeadero de Nootka, aunque sin ningún pronunciamiento de soberanía. La expedición de Bruno de Hezeta, en 1775, sería la primera en declarar los territorios costeros del Noroeste del Pacífico bajo la posesión de la corona española.

Salvador Bernabéu Albert en su obra Trillar los Mares. La expedición 
descubridora de Bruno de Hezeta al Noroeste de América 1775, recopila y anota los diarios de Bruno de Hezeta y de Fray Miguel de la Campa. El hecho de que ambos diarios sean puestos a escrutinio en este análisis, suscita ciertas cuestiones de matiz ideológico con respecto a los parajes que el sujeto colonizador avista en las postrimerías del siglo XVIII por primera vez en las costas del Pacífico en el Noroeste norteamericano. Al contrastar ambos relatos, uno narrado por un navegante y otro por un capellán, se ponen de manifiesto las construcciones narrativas e ideológicas de tales parajes periféricos, así como de los propios sujetos con respecto a esas representaciones.

Las exploraciones en el Pacífico septentrional por parte de la corona española solo tuvieron ciertos conatos de ocupación en Nootka, en la isla de Vancouver, ya que las disputas internacionales entre España y Reino Unido no cejaron de sucederse y los procesos de independencia de los países latinoamericanos estaban ya en ciernes. Estas exploraciones fueron excertas de esa primera fase del paisaje de la "anticonquista", termino acuñado por Mary Louise Pratt, que ilustraba una nueva mirada más crítica y compleja al proceso de posesión y posterior ocupación y colonización, fases que John Elliott identificó en todo proceso de conquista. Pratt en su obra Ojos imperiales. Literatura de viajes y transculturación desvela que en el siglo XVIII se produjo un cambio en el género narrativo de viajes inspirado por la importancia y transcendencia que adquiere la historia natural en el discurso científico y su sistematización y, por otro lado, la carrera internacional por mapear las costas y por definir los territorios como entes de la identidad imperialista que marca la impronta europea en el siglo XVIII. Como todo proceso de transculturización, la colonización del noroeste del Pacífico norteamericano revela una nueva reinvención de las identidades nacionales encontradas en ese espacio fronterizo en el que los espacios son sometidos a transacciones afectivas, gravadas por la empatía o el miedo, la agresión o la alianza.

En sí misma, la visualidad, como forma del modelo cognitivo, contiene 
una capacidad creativa que transciende al espacio y al tiempo, ya que puede denotar predicción y al mismo tiempo visión (Cosgrove 20). La mirada no solo percibe a través de la visión, sino que construye e incluso predice, como los términos "vidente" o "visionario". A diferencia del campo perceptual de tradición medieval, consumado en el orden quirográfico, y sometido a una jerarquía de los sentidos que daba preferencia al oído y al tacto, la supremacía de la vista va a desplazar a las anteriores, donde el orden tipográfico va a primar a partir de los siglos XVII y XVIII. Ya el Renacimiento con su descubrimiento del perspectivismo asumió el carácter deferente de la mirada en sí. Por ende, el concepto del paisaje en la tradición estética europeísta surge a colación de ese perspectivismo que atañe al orden cognitivo. Tanto la invención de la imprenta como de la perspectiva incentivaron un nuevo orden de percepción. La visualidad, al ocupar un prominente lugar en el contexto de la modernidad, en consonancia con la revolución tecnológica imperante que afectaba al orden astronómico y geodésico, no solo produjo un sinnúmero de evidencias de carácter cartográfico que el ambiente cientificista promovió desde el gabinete o las colecciones privadas hasta el museo o el archivo (mapas, cuadros, esbozos, objetos incautados a los indígenas, etc.) sino que vertió las mismas en descripciones textuales dando lugar a un número ingente de diarios de navegación y derroteros que forman parte del archivo imperial.

A lo largo de la historia, la percepción del miedo se ha mostrado como una experiencia subjetiva, ya fuera por la aprensión que infundía en la antigüedad clásica la naturaleza sacralizada, inspiradora de respeto y desconfianza, bien por los rollos o picotas en villas y pueblos para anunciar el castigo en la Edad Media, bien por los lazos de sangre que en esta época se formulaban como salvaguardia frente amenazas religiosas, o bien por el recelo al extranjero que irrumpe con la formación de las naciones-estado. Dos de los grandes miedos que Occidente ha mostrado hasta el siglo XVIII, la naturaleza (vegetación, fenómenos meteorológicos, bosques, animales salvajes, océanos, etc.) y lo 
extranjero (foráneo, incógnito, indígena, etc.) se han diluido a medida que la percepción de estos ha disminuido y se ha proyectado hacia otros espacios y actitudes que abarcan sitios tan inmediatos como los espacios urbanos hasta aquellos más lejanos inspirados por la conquista cósmica. La relación espacial que los exploradores españoles proyectaron en su visión viajera al establecer sus propios confines en un orden de carácter universal se establece para instituir una serie de fronteras cuya amenaza a finales del siglo XVIII surgió por la expansión económica y colonial de las potencias francesa, rusa, y británica:

Cultures differ in the ways they define space but define it if they must. The minimum requirement for security is to establish a boundary, which may be material or conceptual and ritually enforced. Boundaries are everywhere, obviously so in landscapes of fences, fields and buildings, but equally in the worlds of primitive people. Boundaries are everywhere, obviously on different scales. Minimally and perhaps universally, three are recognized: the boundaries of the domain, of the house, and the body. (Tuan 206)

Estos confines, de acuerdo con Yi-Fu Tuan, se configuran en el espectro del dominio, el hogar y el cuerpo. Tales entes se postulan tanto a nivel simbólico como literal y sirven como referencia a nuestro análisis. En la misma línea de pensamiento sobre el espacio y la visión, es ineludible señalar la diferenciación entre parajes (límite) y paisajes (visión) a merced del observador que se identifica y al mismo tiempo contempla y se (re)crea. El paraje se convierte en un paisaje, un contenedor de emoción desde el momento que el observador interviene, delimita e identifica.

\section{Dominio: Tótem o cruz}

En el siglo XVIII, a raíz de las empresas cientificistas de acoso y derribo contra el Imperio español, se reaccionó a ellas enviando diferentes expediciones de límites (Virreinato del Perú en 1777, Nueva España en 1787, Nueva Granada en 
1782) cuyo fin eran fijar las fronteras de los dominios españoles y desvelar los recursos del continente. Tanto la bula papal, Inter Caetera (1493) como el Tratado de Tordesillas (1494) que habían sido utilizados durante siglos por España como vademécum geográfico y potestativo de todas las exploraciones dejó de tener vigencia frente al expansionismo económico y político imperante. A medida que Francia, Gran Bretaña, y Rusia comenzaron a navegar por "el lago español", nombre con el que se conoció familiarmente al Océano Pacífico, el potencial de su zona septentrional y su supuesto mítico paso norte obligó a limitar el orden del dominio bajo fórmulas ya en desuso, pero cuyo rendimiento había surtido un efecto persuasivo ante diferentes grupos indígenas.

En este orden del dominio planteado por Yi-Fu Tuan, desde la conquista española en el siglo $\mathrm{XV}$, se atribuyó a la posesión del dominio su carácter protocolario y por ello se invirtió con solemnidad en el mismo, para que el paraje quedara investido de esa liturgia que confiere el formulario entregado por el Virrey Bucareli y dispuesto con el atrezo y performance de todo tipo de parafernalia: cruces, procesión, la misa, bautismo, descargas, etc. que se remontan a los primeros momentos de la conquista (Seed 1995)

La Instrucción y el Formulario que el Virrey Antonio María de Bucareli y Ursúa (1717-79) entregó a los navegantes presuponen el pilar básico de las posteriores exploraciones con destino al Noroeste del Pacífico. La Instrucción consta de 32 previsiones que se reparten en aquellos dedicados propiamente a la exploración; en ella se enuncian los pertrechos que se habilitan para tal empresa: los cometidos, la forma de proceder para anexionar las tierras, de ahí la existencia del formulario, la escritura diaria de datos por diferentes mandos de la tripulación, así como los objetivos. Un segundo extracto de artículos de carácter preventivo y exploratorio hace alusión directa al posible contacto con potencias extranjeras, y, por último, ocupan gran atención aquellos artículos dedicados al posible encuentro y la relación con los indígenas. Estas disposiciones que las instrucciones dictan pueden resumirse en tres grupos: la formalización 
de la toma de posesión; la recogida etnográfica de la mayor información posible respecto a las tribus (gobierno, religión que profesan, ritos, etc.) se especifica el trueque de objetos versus la apropiación indebida, así como la concesión de obsequios a los indios; la disciplina entre la tripulación; así como el carácter secreto de las expediciones respecto a segundos países. (Olson 26).

El acto legal del Requerimiento, formulario intimidatorio leído a los indígenas en la conquista era utilizado por las tropas como acto de posesión (Seed). Aunque el rito del Requerimiento ya había dejado de utilizarse, "la debilidad intrínseca bajo el punto de vista técnico y político lo hicieron muy cuestionable y como consecuencia moralmente inaplicable, acabó siendo suprimida" (Fernández Heres 68). Sin embargo, ciertas prácticas performativas, en las que entraría el Formulario, el cual mantenía su carácter archivístico, todavía tenía sus ecos fragmentarios en los actos públicos seculares y religiosos asociados con la toma de posesión y colonización del siglo XVIII (García-Caro 70).

Tras navegar durante varias semanas y dejar en su camino las Islas Marías y posteriormente la Isla del Socorro o de Santo Tomé (todas ellas en la costa norte de Alta California), el explorador se ve obligado a bajar a tierra para surtirse de agua, pues las quejas de los marinos debido a su racionamiento se habían encrespado. A pesar de avistar tierra el 6 de junio, las condiciones abruptas de la costa del Pacífico desaconsejaban fondear. Después de reconocer la costa durante algunos días, entró en contacto con algunos indígenas que se acercaron a la nave en sus canoas. Tras un breve acercamiento de los indígenas Yurok con sus embarcaciones y donde intercambiaron pieles, Bruno de Hezeta relata de manera detallada la desconfianza y el recelo que los nativos mostraron posteriormente.

Una vez desembarcados, Bruno de Hezeta narra prolijamente que ascienden por las estrechas sendas hasta llegar a la cumbre donde celebraría una misa y procedería a la instrucción de posesión de tierras, cuya formulación había sido prescrita por el Virrey Antonio María de Bucareli en su Instrucción y Formulario 
de posesión. El tripulante es consciente de que el ritual que inicia intimida a la población, la cual fue precedida de descargas de fusilería y de artillería, así de como vivas al Rey. No sin menoscabo, señala el vasco "de hecho, pasado a la ranchería, los hallé consternados del miedo" (167). Para culminar el ritual de apropiación llevado a cabo mediante el amontonamiento de piedras, el ocultamiento con un mensaje en una botella y la colocación de la cruz, hechos que pareciesen inocentes, el hito de colonización se convierte, no solo en un gesto de apropiación, sino en un acto de vinculación que empieza a configurar un paisaje afectivo tanto para los foráneos, colmado de carga intimidatoria y de júbilo, como de miedo y recelo para los nativos. La afectividad que el dominio representa se impone primeramente mediante el simbolismo para posteriormente circundar el espacio físico del mismo.

El rito de adopción de la civilización cristiana, el bautismo, está asociado con el agua y en el mismo se invoca a la Santísima Trinidad. El marino vasco bautiza esas tierras y nombra el Puerto de la Trinidad a la cala donde arribaron:

Determiné ese día tomar posesión por ser tan señalado de la Santísima Trinidad. Comisioné al amanecer a don Cristóbal de Revilla con algún número de gente armada con el fin de que cogiera las sendas que del continente pasaban a la península que formaba este puerto y dispusiera la capilla donde se había de celebrar la primera misa con el mayor ornato posible $y$, asegurados los pasos de este modo, facilitar el divino culto con toda libertad, que nunca pensaron impedirlo los indios de aquel vecindario, aunque se hallaban acompañados de algunas de las inmediatas rancherías, y, bajando yo en compañía del comandante de la golera, reverendos padres, oficiales y gente armada de ambos buques, fijé la cruz en la playa y, formando en batalla, dimos la primera adoración. (167)

En ese acto de bautizar, el dominio del explorador se expande a bosques y ríos próximos, y nombra a uno de los últimos el río de las Tórtolas. Por otro lado, los ávidos ojos del navegante apuran su mirada pragmática y utilitaria hacia la 
frondosidad de la naturaleza con el fin de aprovechar la "tablazón, curvería y arboladura" para las naves (170), aunque, como despropósito, no haya lugar para el cultivo, y sí para el ganado, pues el pasto es infinito. Por si solo, el acto de nombrar es ambiguo puesto que por una parte apela a la emotividad e intuición del autor y al mismo tiempo a su ineptitud de designar, de evocar una realidad diferente. Hezeta, proclive a la misma iniciativa de anteriores navegantes, invoca su bagaje cultural, así como su imaginario creativo, y de esta maña reconoce hierbas y verduras como el orégano, el apio, las fresas, la yerbabuena, la manzanilla, además de los lirios y rosas de Castilla. O bien designa a una costa de "Cañada" o a un cabo de "Punta Gorda" (172). Una vez pertrechado el dominio, el propio marino certifica la conveniencia de establecimiento del Puerto de la Trinidad, no sólo por el principal motivo de colonización que es impartir el Evangelio, para no contrariar a su destinatario, "primer objeto de nuestro soberano" (172), sino por las ventajas que ofrece para desembarcar naves de mediana magnitud. Se da así cumplida gestión del proyecto del viaje.

Una vez dejado el Puerto de la Trinidad costearon hasta llegar a la nombran como la Rada de Bucareli (176). Los indios que estas tierras cobijan, señala Hezeta, son "apacibles, dóciles y tímidos" (170). La anticonquista, según Pratt, como enunciación científica y sentimental, formuló los mecanismos de expansionismo europeo, ajenos a cualquier uso de la "violencia" mediante la observación de los territorios explorados, la apropiación de recursos, así como el control administrativo. La deslegitimización de métodos y procederes violentos llevó a las potencias en expansión a desarrollar un intervencionismo que legitimara los intereses occidentales. Las estrategias íntegras desplegadas por los navegantes en este periodo, cabe recordar la máxima del Virrey Bucareli apelando al trato a los indios mediante "la prudencia, suavidad y maña", se alinean con el fin último que es el de la apropiación (Velasco 120).

Si el relato del marino se adapta con total fidelidad a la interpretación persuasiva, la narración de Fray Miguel de la Campa refleja estos mismos 
sucesos, supeditándose al detalle, y en este caso a su protagonismo ya que fue él el que celebró la misa junto a su colaborador Fray Benito de la Sierra. En el acto de posesión y el bautizo de aquellas tierras nos advierten de su transcendencia y significación, como hemos mencionado anteriormente. Sin embargo, me detengo en el pasaje posterior que describe por contraste al discurso de Hezeta, el miedo que se instiga a las rancherías y que provoca una situación absurda:

Al bajar nos encontramos cerca de la playa cuatro indios y al uno, que la tarde antes lo juzgamos el más advertido, le dijo el capitán de la goleta que dijera: Viva Carlos Tercero, y él, muy alegre, repetía con nuestra gente: Viva Carlos Tercero, sin causarle novedad el estruendo de la artillería que con orden respondió a los saludos que hizo en la playa la gente con los fusiles. No lo pasaron con tanto gusto los que estaban en las rancherías, pues, al ruido del cañón y lo recio del eco que resonaba en los montes, los hizo temblar de miedo, como ellos mismos nos explicaron a la tarde que fuimos, a visitarlos y se les explicó por señas lo que había, dándoles a entender que eran nuestros amigos. (204)

El rito del dominio militarista (desembarco, desfile, descargas de cañón) dentro del orden simbólico que se impone en la zona de contacto, cede paso al ámbito religioso investido por un rito que impone, juzga y somete, aunque para el indígena estuviera amparado en la incredulidad. En un acto de confabulación sin límites que llega incluso a dialogar con el nativo y asegurarse su complicidad, el capellán nos refiere:

Y sin decirles nada de la cruz, ellos, de su motivo, dijeron que no la quitarían y que cuidarían de que otros no la quitasen, que, cuando volviéramos, la hallaríamos allí. (Campa 207)

El "Trinidad Museum" en California guarda restos de aquella cruz que posteriormente divisó y registró en su diario de navegación el capitán 
Vancouver en 1793 y a la postre el oficial de la goleta Columbia, Peter Corney en 1817 (Cox 8).

Los asentamientos indígenas del Pacífico Noroeste, erigidos en la mayoría de los casos en la cercanía de los lechos fluviales o de la costa marítima, concebidos en función de su actividad cazadora y recolectora, distinguió que el orden de su dominio se constituyera en torno a sus fuentes de manutención primordialmente. En aquella zona de contacto, la cruz no podía interferir en el imaginario del sostén de la tribu, conferido al sustento de esta y a la supervivencia, su dominio no se veía perturbado. El tótem, cuyas atribuciones sobrenaturales y anímicas amparaba las necesidades espirituales de la tribu sería usurpado. La apropiación simbólica que implicó el acto de posesión supuso una transformación del espacio geográfico que revela todo un proceso cultural que debe ser cotejado respecto a la construcción subjetiva y emocional archivada como empresas celebratorias en Occidente desde la conquista columbina cuya mayor apoteosis supuso la celebración del V Centenario en 1992 y cuyo origen data de comienzos del siglo XX, a raíz de la primera celebración en España en 1914 con el día de la Raza y por extensión al resto de países hispanos. Estas celebraciones se expandieron por todo el continente americano hasta su actual cuestionamiento o transformación en honor a la herencia indígena como proceso decolonizador.

\section{Morada: entre el barco y la ranchería}

El ámbito de la morada en la cosmovisión naval abriga una tensión permanente: por una parte está reducido al espacio de la embarcación, que por su intrínseca naturaleza se somete a las jerarquías y a las vicisitudes del mismo; la convivencia, la renuncia o el carácter letal de enfermedades como el escorbuto, tifus, sarampión, viruela, entre otras; y por otra, al encuentro con otras tripulaciones o con los propios indígenas en sus rancherías, reducto de intereses políticos, conflictos lingüísticos o deserciones. 
Es interesante notar que la mortalidad entre los años 1776-80, debido al escorbuto era del $83 \%$, y a medida que se supera la avitaminosis, su caída disminuye al 33,3\% entre 1810-12 debido a enfermedades asociadas al ámbito de la navegación, sobre todo la del tifus (Pérez Mallaina). De hecho, una de las principales preocupaciones de Bruno de Hezeta era renovar la aguada, con el fin de evitar la putrefacción:

El día 21 de mayo resolví juntas y tomar informes sobre la recalada que debíamos hacer para surtirnos de agua, de que estábamos escasos, y la marinería, cansada ya de sufrir la poca que se le suministraba, necesitaba el alivio que deseaba darle por los consideraba fatigados con extremo. (Hezeta 164)

A medida que la tripulación se va diezmando y el escorbuto hace mella, los oficiales exponen así a Bruno de Hezeta el temor a sucumbir a la muerte:

Que la marinería estaba enferma en términos que solo muy pocos podían asistir a la guardia, y aun de éstos, los más picados de escorbuto e incapaces de atender a la maniobra en uno de los muchos días críticos que suelen ocurrir en la mar, y así exponía conocidamente el buque y tripulación al riesgo de perecer. (180)

En principio, las quejas de los subalternos fueron repudiadas por el comandante Bruno de Hezeta, quien pretendía subir, como las instrucciones del Virrey Bucareli demandaban, hasta los 65 grados de latitud norte. La bahía que nombra de la Asunción le lleva a determinar que posiblemente fuera el estrecho que Fuca descubrió en 1692, sin poder asegurarlo. Ante la tensa y penosa situación tras la muerte de varios marinos por el escorbuto, finalmente determinó volver a Monterrey y posteriormente a San Blas.

El avistamiento de la boca del río Columbia, así como los escarceos con los indígenas Quinault resumen el viaje de vuelta, además de las descripciones 
reiteradas del lamentable estado de la tripulación. Fray Miguel de la Campa llega a contabilizar hasta 36 enfermos de escorbuto, 50 con otras dolencias, 12 muertos, de un total de 92 expedicionarios que arriban a Monterrey el 31 de agosto. Se dio además la circunstancia del suceso en el que tuvo lugar a la separación de la otra goleta a finales de julio y al mando de Juan Francisco de la Bodega y Quadra. Fray Miguel de la Campa narra los hechos esta, el encuentro no muy amigable con los indios en el puerto que bautizaron de los Remedios, la toma de posesión de la Rada de Bucareli (hoy día llamada Bucareli Bay, en Alaska), donde "experimentaron calor, que juzgaron sería por el mucho fuego que salía de un volcán” (227), el reconocimiento de la isla de San Carlos, hasta llegar presuntamente a la altura de los 65 grados 40 minutos de latitud norte y retornando a Monterrey, hecho que se produjo el 5 de octubre. Después de la necesitada convalecencia, partieron hasta San Blas y dieron fin a la expedición el 20 de noviembre de 1775.

Además de los trastornos médicos, el ámbito del barco será limitado, falto de intimidad y en muchos casos de ocio. En ese espacio restringido se contraponen las desavenencias y la concordia y solamente la jerarquización va a permitir solventar la mayoría de los incidentes. Pérez Mallaina alude a las transformaciones en las relaciones laborales en las naos que se produjeron desde la Edad Media hacia la Edad Moderna, en consonancia con la evolución económica de estos periodos. La camaradería incipiente del medioevo daría lugar a la proletarización de los marineros (Pérez Mallaina).

A menudo la insubordinación, la deserción, o la incapacitación, amenazaron el orden de convivencia, y por tanto el de la morada. Por una parte, constriñen el orden doméstico, y por otra, la relación con los indígenas. De hecho, uno de los conflictos surgido nada más comenzar la expedición fue la perturbación de las facultades mentales padecida por uno de los tenientes de navío, Miguel Manrique y que tuvo que ser reemplazado. El mando del paquebote fue cedido a Juan de Ayala y la goleta a Juan Francisco de la Bodega y Quadra. El piloto 
Cañizares relata, a petición de Bruno de Hezeta, la sucesión de anormalidades que el teniente de Navío sufrió y que puso en peligro la vida de los navegantes:

Me mandó aprontar las banderas con toda celeridad, inmediatamente sacó pólvora y tiró tres cañonazos e izó bandera encarnada al tope mayor. Inmediatamente, hizo con toda superioridad y rectitud tirar otro cañonazo y mando sacar todas las armas. Casando dos pistolas, sin consentir arrimarse a nadie a su lado, mandó en alta voz largar los tomadores de las gavias y cazarlas, y marearlas, para cuya maniobra alternaba con la voz y señalaba con la pistola que tenía carga. Después de esta maniobra, mandó picar el cable, a lo que, si se dilata el contramaestre, lo mata. (Bernabéu 71)

En ese orden, el desembarco siempre produjo temeridad ante lo desconocido y sometido a otros hechos que perturbaron la concordia entre la marinería. Las continuas deserciones llevaron a confrontaciones con la población nativa. La disyuntiva entre cautivos y desertores se adviene no tanto como una oposición de términos, sino como un oxímoron.

Practiqué la misma diligencia de proveerme de aguada, leña y lastre. A la primera barcada que de estos géneros se condujo, se restituyó el grumete Pedro Lorenzo, uno de los desertores que el día anterior cito, a quien, habiéndole tomado declaración, dijo que, insinuado del jefe de la ranchería india para que se quedara en su compañía, ofreciéndole el dominio de aquellas tierras con cuantos recursos tenían para la manutención, había determinado quedarse y que, conducido de los indios y auxiliado de sus comestibles, lo habían conducido y mantenido con guardia de vista en la frondosidad de una cumbre inmediata a este fondeadero, pero que, descuidados los centinelas que le acompañaban y arrepentido de sus delito, intentó la fuga, que se verificó. (169)

A ojos del explorador, la morada indígena es contemplada solamente desde el exterior, el propio Fray Miguel de la Campa confiesa la imposibilidad de visitarla "Las cierran por dentro con una tabla corrediza y así no vimos lo que 
tenían" (202). Por otro lado, según el fraile, la marinería describe la visita a algunas de las casas subterráneas que describen con el suelo entablado donde mantienen un fuego rodeado de piedras en el centro y en el que se celebró una cremación de un nativo. "Según se explicaron, se había muerto uno y lo estaban quemando, lo que se conocía por el mal olor que salía de la casa subterránea" (205).

La reacción del Imperio español fue la de defenderse de las aspiraciones de colonización internacionales, sobre todo, del Imperio británico. Absurdamente, el dominio del mundo indígena se vio amenazado por la irrupción del hombre europeo que subestimó el dominio natural que representaban las rancherías de los indígenas. La morada se convierte en este tipo de narrativa oceánica, paradójicamente en un confín lesivo, que más allá de salvaguardar, avizora la discordia y la contrariedad, usurpa cualquier connotación afectiva del significado literal que el refugio pudiera albergar, ya fuera desde la mirada que reporta el capellán o desde la de los marineros.

\section{Cuerpo: la vestimenta y la desnudez}

Consustancial a las exploraciones iniciadas desde los comienzos de la conquista fue la descripción de los seres humanos como parte del paisaje, así lo demuestra la escritura etnográfica de Cristóbal Colón, Fray Bernardino de Sahagún, Fray Bartolomé de las Casas, José de Acosta, entre otros. Aunque la antropología no se constituyó con una metodología científica hasta mediados del siglo XIX, toda la modernidad fue primordial en su configuración como elemento en cierne de la anticonquista (Pratt), por parte de los países colonizadores. En estos textos referidos, además de la composición tradicional que refiere la transición del paraje (naturaleza) al paisaje (cultura), las categorizaciones sutentadas por las descripciones fisiológicas, aparecen aquellos rasgos visibles que detentan la presencia del explorador, ya sea por la inclusión de un léxico temático en el 
que se contrastan términos comparativos, ya fueran por las formas de vestir, los rasgos fisionómicos, o por el examen minucioso, introspectivo.

Uno de los topoi que se repite en el mundo en las exploraciones es el tratamiento que los navegantes hacen en sus descripciones respecto a la desnudez del indígena. La proyección del cuerpo indígena supone la propia representación del sujeto europeo, abocado a los deseos y carencias masculinas, actantes de la representación. Es sabida la interpretación cristiana que desde las primeras conquistas se hizo de la desnudez con la falta de decoro, de religión, de cultura, identificada con el pecado original y que, contradictoriamente, la misma defensa del indígena provenga de la carencia de vestimenta identificada con la pureza y la carencia de egoísmo.

Aunque el tono grotesco corporal, en términos bakhtinianos, fueron reducidos a la perspectiva científica que las exploraciones demandaban, tuvo diferentes representaciones en la performance que los nativos encarnaron en otros encuentros y del que nos dio debida cuenta José Mariano Moziño en una de las posteriores exploraciones (García Sánchez). La jerarquización impera dentro del orden moral más estricto, donde el rey representaba la cabeza de todo un cuerpo conformado por sus súbditos. Como señala Alejandra Areyana Espinoza, el objeto de los procesos de "individualización del cuerpo de los súbditos es extender sobre ellos la dignidad de la persona del rey (autoridad), lo que se ha Ilamado "ennoblecimiento del cuerpo" de los súbditos (354).

La fisonomía de ésta y comarcana indiada es de mediana corpulencia, robustez y agilidad, sin hermosura en uno y otro sexo; la color trigueña, el pelo largo y lacio, ojos negros y alegres, barbilampiños. No usan los hombres de ninguna vestidura, ni aún para ocultar lo más deshonesto, y solo en el caso de que les obligue el frío, se cubren de pieles bien adobadas de venados, cíbolos, berrendos, osos, nutrias y de una especie de mantas tejidas de pellejos de conejo y otros, que su flexibilidad permite aquel beneficio sin el desagrado de la aspereza. 
Las mujeres se cubren desde la cintura hasta las rodillas de un faldellín de badana o hierbas, que unos rematan en diferentes hilos como fleco y en otro empieza y acaba así, que, con el cuidadoso manejo que les dan, lo hacen honesto, carácter muy propio de su inclinación.

Este sexo, cuidadoso de los afeites como en todas partes, gusta de los abalorios, pero no hacen mayor aprecio de las bayetas y paños. (170)

Sobre las vestimentas de la población indígena, Fray Miguel de la Campa recaba en su apreciación:

Los hombres andan del todo desnudos y solo usan por defenderse del frío unos cueros de venados agamuzados, con el que lo que le ponen por dentro para mayor abrigo. Con lo mismo se cubren las mujeres, que, a más de eso, hacen para atrás un género de enaguas de lo mismo, las que procuran adornar con sus labores de palma, y por abajo les dejan muchas tiras muy delgadas a manera de fleco y por delante unos delantales de carrizos. (203)

Sabemos, a raíz de los estudios de Michel Foucault, que el cuerpo está franqueado por relaciones de poder, y sometido a la representación por parte de los discursos que lo vigilan, reconocen, inspeccionan o castigan, de acuerdo con la norma preestablecida. La vestimenta, metonimia del conocimiento, desplaza al cuerpo desnudo hasta lo pecaminoso, donde lo "deshonesto", los órganos sexuales, vejan la mirada del expedicionario. En este sentido, el cuerpo del indígena masculino, solamente dispensado por el frío, reactiva el discurso imperial que encuentra contradictoriamente en la mujer, "su inclinación honesta". No solo la vestimenta constituye una metonimia en la construcción de la otredad, sino que también el vello desde la antigüedad clásica, identificable en la tradición bíblica, opera notoriamente; la barba supone un signo de masculinidad, elemento de virilidad dentro de los parámetros universales que dicta la cristiandad, y que por extensión blindarán las características del caballero al mundo occidental; el linaje, la hombría, 
la sabiduría, así como la autoridad del varón. El nativo, a ojos de Bruno de Hezeta, contrasta con la "falta de hermosura" y la "falta de vello facial", cuyo detrimento entra en el orden de la feminización.

La desnudez, esencia de las utopías que conforma el paraíso edénico, se desplaza e identifica a ojos imperiales en este mundo terrenal a un mundo sin civilización, o, mejor dicho, cuya civilización y visión del paisaje son negadas o invisibilizadas. Desde la colonización colombina, el cuerpo del indígena fue representado como una suma de carencias encarnadas por su pasividad, mudez, feminización, docilidad, como entidad tribal. Es significativo que la descripción de Bruno de Hezeta diste de la individualización para colectivizar a la comunidad apercibida en términos tales como la "comarcana indiada", o bien por la división genérica entre mujeres y hombres. Esa necesidad de generalización, que invocó el sistema de Linneo para categorizar la realidad avistada, marca desde el principio la ausencia de personalización, característica propia del discurso colonial que además moldea la descripción en torno a la visión corporal sistematizada, capaz incluso de atribuirle o privarle de "hermosura" al mismo. A pesar de que su desnudez perturba al comandante, las pieles que cubren la misma (venados, cíbolos, berrendos, osos, nutrias), nos remiten directamente al objeto de deseo que estas exploraciones tuvieron por parte de las expediciones rusas o francesas. No en vano, es preciso recordar el generador de tales expediciones, iniciadas como reacción a las noticias propiciadas por el Imperio ruso y su llegada en busca del comercio de pieles.

La geografía contemporánea ha atestiguado que no hay humanidad sin paisaje y paisaje sin humanidad (Martínez de Pisón 131). Como en tantos otros encuentros humanos, los exploradores del Noroeste del Pacífico iniciaron la construcción cultural de Europa y del territorio que divisaron mediante las sensibilidades que proyectaron, ya fuera por su asombro, perturbación, maravillamiento, extrañeza o miedo. La huella glaciar en el Septentrión del Pacifico excavó un paisaje accidentado, una artesa costera llena de coníferas, 
acantilados, islas, oleaje, neblinas y copiosa lluvia, antípoda del mítico paraíso perdido. Los paisajes se definieron no solo como representaciones, sino como identificaciones por cuanto los sujetos divisaron y al mismo tiempo se proyectaron en los mismos. Tal identificación, auspiciada en la visión asimilacionista que prevalece en la proyección de valores propios, no es otra que la proyección de valores universales que la modernidad construyó como emblema de progreso. Las potestades definidas al principio de este ensayo por el dominio (Pacífico Septentrional), la morada (rancherías) y el cuerpo (pieles, desnudez), fueron puestas en disputa por un Occidente que reinventó su identidad, a merced de sus propios deseos y carencias, sus pretensiones y miedos.

La configuración de un nuevo mapa geopolítico a finales del siglo XVIII y comienzos del siglo XIX, a raíz de los procesos de Independencia y de expansión de los EE. UU. (Venta de la Luisiana en 1803, Tratado Adams-Onís 1819-1821) contribuiría a una nueva visión de la costa del Pacífico Noroeste norteamericano. Sin duda, la llegada a la desembocadura del río Columbia por parte de la expedición transcontinental de Lewis and Clark en 1805 difiere de la mirada oceánica que desde la borda los marinos del imperio ruso describieron en 1741 (Bering y Aleksei Chirikov), la que los españoles relataron en 1775 (Bruno de Hezeta), o la de la corona británica en 1778 (James Cook); estas múltiples visiones desvelan el paisaje de la modernidad en un cuadro cuyos matices y gradaciones imperiales revelan la construcción truncada del paisaje del Noroeste. El sentido de posesión que los diferentes imperios formularon respecto a la colonización del Noroeste del Pacífico norteamericano revela en este análisis que las prácticas coloniales europeas ratificadas por los diarios de navegación a sus respectivas coronas vislumbran paisajes culturales identitarios de cariz nacionalista.

El descubrimiento y los logros cartográficos del continente americano que fueron completados con las costas del Noroeste del Pacífico Septentrional 
a finales del siglo XVIII no supusieron solamente su proyección física, sino también la creación de una entelequia fronteriza entre la geografía física y la emocional que irrumpió en el dominio indígena. Confluyen en ese nuevo orden la expansión económica de las grandes potencias internaciones en lid en aquella terra nullius, que, aunque divisara al indígena desestimó su humanidad, reincidiendo en la construcción de un paisaje fragmentario que aún perdura.

\section{Obras Citadas}

Araya Spinoza, Alejandra. El castigo físico: el cuerpo como representación de la persona, un capítulo en la historia de la occidentalización de América, siglos XVI-XVIII. 2006. Repositorio.uchile.cl/handle/2250/138359. Consultado 3 de marzo, 2019.

Bakhtin, M. M., et al. Teoría y estética de la novela. Taurus, 1991.

Bernabéu Albert, Salvador. Trillar los mares: (La Expedición descubridora de Bruno de Hezeta al Noroeste de América, 1775). CSIC, 1995.

Cosgrove, Denis E. Geography and Vision: Seeing, Imagining and Representing the World. I.B. Tauris, 2008.

Cox, Alexandra. Report on Trinidad Cross artifact (HO2010.10). Trinidad Museum

Society. (2015). www.trinidadmuseum.org/wpcontent/uploads/Report_Trinidad_ Cross Artifact.pdf. Consultado 18 de marzo, 2019.

Elliot, John H. Empires of the Atlantic World: Britain and Spain in America 1492-1830. Yale University Press, 2006.

Fernández Heres, Rafael. "Requerimiento y opinión de los franciscanos y dominicos de Caracas en 1631" Academia Nacional de la Historia (Venezuela). Boletín de la Academia Nacional de la Historia, vol. 89, no. 356, 2006, pp. 45-72.

Foucault, Michel, Vigilar y castigar: nacimiento de la prisión. Siglo XXI, 1997.

García Caro, Pedro. "Performing to a Captive Audience: Dramatic Encounters in the Borderlands of Empire." Edited by John Morán González and Laura Lomas. The Cambridge History of Latina/o American Literature. Cambridge University Press, 2018, pp. 51-73.

García Sánchez. José M. "Noticias de Nootka: las fronteras discursivas de José Mariano Moziño Losada" Cuadernos de Aldeeu, vol. 27, no. 1, 2014, pp. 61-76. 
Martínez de Pisón. “Los componentes geográficos del Paisaje”. Paisaje y pensamiento. Edición de Javier Maderuelo. Abada Editores, 2006.

National Snow and Sea Data Center. University of Colorado at Boulder, 2019,

nsidc.org/data/seaice_index. Consultado 18 de marzo, 2019

Olson, Wallace M. Through Spanish Eyes: the Spanish Voyages to Alaska, 1774-1792. Heritage Research, 2002.

Pratt, Mary Louise. Imperial Eyes: Travel Writing and Transculturation. Routledge, 1992.

Pérez Mallaína, Pablo E. Los hombres del océano: Vida cotidiana de los tripulantes de las flotas de Indias, siglo XVI. Publicaciones de la Diputación de Sevilla, 1992.

Said, Edward W. Culture and Imperialism. Knopf, 1993.

Seed, Patricia. Ceremonies of Possession in Europe's Conquest of the New World, 14921640. Cambridge UP, 1995.

Tuan, Yi-Fu. Landscape of Fear. University of Minnesota Press, 2014.

Velasco Ceballos, Rómulo. La Administración de D. Frey Antonio María de Bucareli y Ursua. Publicaciones del Archivo General de la Nación. 1936. 